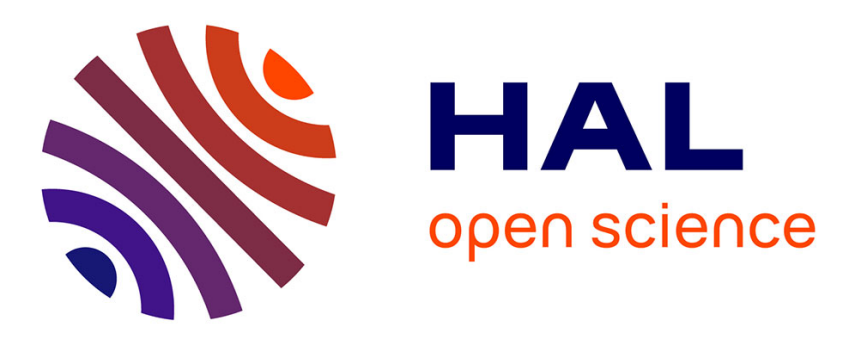

\title{
On the hydrogen bonding structure at the aqueous interface of ammonium-substituted mica: A molecular dynamics simulation
}

\author{
L. Narasimhan, Andrey G. Kalinichev
}

\section{- To cite this version:}

L. Narasimhan, Andrey G. Kalinichev. On the hydrogen bonding structure at the aqueous interface of ammonium-substituted mica: A molecular dynamics simulation. Zeitschrift fur Naturforschung a, 2013, 68, pp.91-100. 10.5560/ZNA.2012-0101 . in2p3-00768710

\author{
HAL Id: in2p3-00768710 \\ https://hal.in2p3.fr/in2p3-00768710
}

Submitted on 23 Dec 2012

HAL is a multi-disciplinary open access archive for the deposit and dissemination of scientific research documents, whether they are published or not. The documents may come from teaching and research institutions in France or abroad, or from public or private research centers.
L'archive ouverte pluridisciplinaire HAL, est destinée au dépôt et à la diffusion de documents scientifiques de niveau recherche, publiés ou non, émanant des établissements d'enseignement et de recherche français ou étrangers, des laboratoires publics ou privés. 
Running Title: Molecular dynamics of isotopically substituted ammonium-mica

On the hydrogen bonding structure at the aqueous interface of ammonium-substituted mica: A molecular dynamics simulation

\author{
Narasimhan Loganathan ${ }^{\mathrm{a}}$, Andrey G. Kalinichev ${ }^{\mathrm{a}, \mathrm{b}, *}$ \\ ${ }^{a}$ Laboratoire SUBATECH (UMR-6457), Ecole des Mines de Nantes, F-44307, Nantes, \\ France \\ ${ }^{\mathrm{b}}$ Departments of Chemistry and Geological Sciences, Michigan State University, \\ East Lansing, MI 48824, USA
}

*Address for reprint requests: Dr. Andrey G. Kalinichev, e-mail: kalinich@subatech.in2p3.fr

Dedicated to Prof. Alfred Klemm on the occasion of his 100th birthday. 


\section{$\underline{\text { Abstract }}$}

Canonical NVT-ensemble molecular dynamics (MD) computer simulations were performed for an aqueous film of 3nm thickness adsorbed at the (001) surface of ammoniumsubstituted muscovite mica. The results provide a detailed picture of the near-surface structure and topological characteristics of the interfacial hydrogen bonding network. The effects of $\mathrm{D} / \mathrm{H}$ isotopic substitution in $\mathrm{N}(\mathrm{H} / \mathrm{D})_{4}{ }^{+}$on the dynamics and consequently on the convergence of the structural properties have also been explored. Unlike many earlier simulations, a much larger surface area representing 72 crystallographic unit cells was used, which allowed for a more realistic representation of the substrate surface with a more disordered distribution of $\mathrm{Al} / \mathrm{Si}$ isomorphic substitutions in muscovite. The results clearly demonstrate that under ambient conditions both interfacial ammonium ions and the very first layer of water molecules are H-bonded only to the basal surface of muscovite, but do not form H-bonds with each other. As the distance from the surface increases, the H-bonds donated to the surface by both $\mathrm{N}(\mathrm{H} / \mathrm{D})_{4}{ }^{+}$and $\mathrm{H}_{2} \mathrm{O}$ are gradually replaced by the $\mathrm{H}$-bonds to the neighboring water molecules, with the ammonia ions experiencing one reorientational transition region, while the $\mathrm{H}_{2} \mathrm{O}$ molecules experiencing three such distinct consecutive transitions. The hydrated $\mathrm{N}(\mathrm{H} / \mathrm{D})_{4}{ }^{+}$ions adsorb almost exclusively as inner-sphere surface complexes with the preferential coordination to the basal bridging oxygen atoms surrounding the $\mathrm{Al} / \mathrm{Si}$ substitutions. 


\section{Introduction}

Molecular scale understanding of mineral-water interactions is crucial for many problems of geochemistry, environmental sciences and materials sciences [1-5]. Adsorption of aqueous species on mineral surfaces often controls their distribution in both natural and technological settings [6-10]. In particular, due to their strong ion adsorption capacity, deep natural clayey formations are often considered as preferred sites for geological nuclear waste disposal and storage. For the same reason, clays are a major component of engineered geochemical barriers for the containment of toxic wastes. The uptake of radionuclides and other contaminants by layered clay minerals is the principal retention mechanism limiting their mobility in the repository environment.

The molecular-scale details of the interaction of aqueous species with mineral surfaces are controlled, on the one hand, by mineral substrate structure, composition and surface charge distribution [10-11], and on the other hand - by the presence of surface water molecules which create local interfacial hydration environments significantly different from the bulk [12]. This clearly imposes the need to have better insights into the structural and dynamic characteristics of the interfacial hydrogen bonding networks [13].

In recent years, much attention has been paid to the investigation of the molecularscale physical properties of aqueous solutions on the surfaces of muscovite mica, $\mathrm{KAl}_{2}\left(\mathrm{Si}_{3} \mathrm{Al}\right) \mathrm{O}_{10}(\mathrm{OH})_{2}$, both by experimental [14-18] and computational molecular modelling [19-26] techniques. Due to its atomically smooth surface after cleavage along the basal (001) crystallographic plane, mica is a preferred mineral substrate for many surface-related experimental studies, and, at the same time, mica represents a good simplified model of clays, which typically have a similar layered crystal structure, being much more diverse compositionally, which complicates their direct molecular simulation [27]. 
Recent advances in surface-specific experimental techniques, such as sum frequency generation vibrational spectroscopy (SFG) [17], surface force apparatus (SFA) [28-30], Fourier transform infrared spectroscopy (FTIR) [18] and synchrotron X-ray reflectivity [1, 5, $9,15,16,31]$ provide indispensable information on the structure of interfacial aqueous films. However, the results obtained from these experiments are often difficult to interpret on the molecular scale to quantify the underlying physico-chemical processes. Concurrently, molecular computer simulations have become one of the most important tools in the study of such interfacial systems and phenomena by providing the atomistic information in many ways complementary to the experimental data. For instance, the results of Monte Carlo (MC) simulations by Park and Sposito [23] and Malani et al. [20] on the adsorption of water adjacent to muscovite mica are consistent with the X-ray reflectivity measurements [31]. On the other hand, molecular dynamics (MD) simulations by Wang et al. $[12,26]$ on the hydrated muscovite (001) surface suggest the probable orientational ordering and the diffusive restriction of water molecules normal to the surface. Similar studies were performed by Sakuma et al. $[24,25]$ on the structure of mica-water interfaces containing different surface exchanged cations. All these simulations were in good agreement with available experimental observations.

It is important to emphazie that most of the experimental and molecular modelling results discussed above considered either alkali metals or hydronium ion as the charge compensating cations. The ammonium cation, $\mathrm{NH}_{4}{ }^{+}$, represents an additional interesting species in this respect. It is known from earlier studies that most of the nitrogen present in the Earth's crust is stored in minerals in the molecular form of ammonium. This ion has a comparable ionic size with $\mathrm{K}^{+}$and can easily substitute for $\mathrm{K}^{+}$in the muscovite mica and other K-bearing phyllosilicates [32]. Ammonium is an important cationic functional group present in many polymers and other organic molecules, which is responsible for their strong 
interactions with clays and clay-related mineral surfaces [27, 33] and for the formation of many useful organo-inorganic nano-composites for diverse technological and environmental applications.

From a more fundamental standpoint, the $\mathrm{NH}_{4}{ }^{+}$ion represents an extremely interesting molecular probe of the structure, dynamics, and topology of the hydrogen bonding network at the mineral-solution interface. Indeed, $\mathrm{H}_{2} \mathrm{O}$ molecules can donate approximately two hydrogen bonds to the neighboring $\mathrm{H}$-bond acceptors (typically to $\mathrm{O}$ atoms of the substrate surface or to other $\mathrm{H}_{2} \mathrm{O}$ molecules) and can accept two H-bonds from other molecules [13]. The hydronium $\mathrm{H}_{3} \mathrm{O}^{+}$ions, which are often assumed to be significantly displacing the $\mathrm{K}^{+}$ions at the mica surface $[31,34]$, can donate three H-bonds, but usually accept none. This creates a defect in the interfacial H-bonding network. On the other hand, $\mathrm{NH}_{4}{ }^{+}$ions can only donate four H-bonds, but cannot serve as acceptors. Thus, the presence of ammonium at the surface could alter the structure and dynamics of the interfacial H-bonding network in ways different from the effects of $\mathrm{H}_{2} \mathrm{O}$ and $\mathrm{H}_{3} \mathrm{O}^{+}$. The exchange of hydrogen with deuterium $\left(\mathrm{NH}_{4}{ }^{+}\right.$to $\left.\mathrm{ND}_{4}{ }^{+}\right)$ in can lead to different dynamic effects on the local H-bonding network topology and reorganization.

The main objective of the present study is to use molecular dynamics computer simulations for quantitative characterization of the local structural environments of ammonium ions and water molecules at the hydrated surface of muscovite, the topology of the interfacial hydrogen bonding network and its dependence on the distance from the surface, and the possible effects of the $\mathrm{D} / \mathrm{H}$ isotopic substitution in ammonia ions on their adsorption mechanisms at the muscovite surface.

\section{Simulation Methods and Analysis}


Muscovite mica is a 2:1 layered aluminosilicate with the unit cell formula $\mathrm{KAl}_{2}\left(\mathrm{Si}_{3} \mathrm{Al}\right) \mathrm{O}_{10}(\mathrm{OH})_{2}$. Its structure consists of so-called TOT layers (a dioctahedral layer of Al hydroxide sandwiched between two layers of $\left[\mathrm{SiO}_{4}\right]$ tetrahedra linked together in 6member rings) stacked along the crystallographic $z$ direction. One out of four Si atoms in the tetrahedral layers is substituted by $\mathrm{Al}$. This isomorphic $\mathrm{Al} / \mathrm{Si}$ substitution results in a net negative layer charge that is compensated by the presence of interlayer $\mathrm{K}^{+}$ions. The $\mathrm{Al}$ substitutions in the tetrahedral layer obey Lowenstein's rule, which avoids the Al-O-Al linkages [35]. All interlayer $\mathrm{K}^{+}$ions are located at the center between the two TOT layers. In contrast to many earlier simulations, we have created a larger simulation cell, which consisted of $12 \times 6$ crystallographic unit cells of muscovite with the total lateral dimensions of $L_{x}=$ $62.42 \AA$ and $L_{y}=54.14 \AA$. This allowed to represent the layer charge distribution in muscovite more realistically than it was previously possible. In particular, special care was taken to place all $\mathrm{Al} / \mathrm{Si}$ substitutions randomly within the tetrahedral layer, and a careful investigation was performed to ensure that these random distributions of Al-substituted sites do not lead to any distortions in the Al octahedral layer.

The tetrahedral layer consists of connected hexagonal rings with $\mathrm{Si}_{4} \mathrm{Al}_{2}$ and $\mathrm{Si}_{5} \mathrm{Al}_{1}$ compositions. The six basal oxygen atoms bridging $\mathrm{Si}$ and $\mathrm{Al}$ atoms of the same hexagonal ring are in the vertices of the two equilateral triangles and are responsible for the formation of ditrigonal cavities in the mica surface. The local differences of the charge distribution around a substituted Al site were taken into account by using the CLAYFF interatomic potential model [36], where the bridging $\mathrm{O}$ atoms in the Al-O-Si linkages $\left(\mathrm{O}_{\mathrm{bts}}\right)$ bear $\sim 11 \%$ more negative charge than the normal bridging oxygens in $\mathrm{Si}-\mathrm{O}-\mathrm{Si}\left(\mathrm{O}_{\mathrm{b}}\right)$.

In our $\mathrm{N}(\mathrm{H} / \mathrm{D})_{4}{ }^{+}$-muscovite models, all interlayer $\mathrm{K}^{+}$ions were replaced by $\mathrm{N}(\mathrm{H} / \mathrm{D})_{4}{ }^{+}$. The model $\mathrm{N}(\mathrm{H} / \mathrm{D})_{4}{ }^{+}$exchanged muscovite surface was built by cleaving the muscovite structure along the (001) plane at the middle of the interlayer space. After cleavage, each 
surface retains half of the interlayer $\mathrm{N}(\mathrm{H} / \mathrm{D})_{4}{ }^{+}$ions. The simulation cell consists of two muscovite TOT layers of a total thickness $\sim 20 \AA$ separated from the subsequent layers through a cleavage along the plane of the interlayer $\mathrm{N}(\mathrm{H} / \mathrm{D})_{4}{ }^{+}$ions and pulling apart the cleaved surface to $\sim 96 \AA$. This separation effectively eliminates the influence of one hydrated interface on another within the three-dimensional periodic boundary conditions that were applied in all simulations. As a result of the cleavage, each of the two external surfaces of muscovite retained the ion coverage of one $\mathrm{N}(\mathrm{H} / \mathrm{D})_{4}{ }^{+}$per unit cell area, compared with the usual bulk concentration of two $\mathrm{N}(\mathrm{H} / \mathrm{D})_{4}{ }^{+} / \mathrm{A}_{\mathrm{uc}}$ in the interlayer of muscovite. A schematic representation of the simulation cell is shown in Figure 1.

Periodic boxes with identical lateral dimensions containing $\mathrm{H}_{2} \mathrm{O}$ molecules at bulk liquid water density of $1.0 \mathrm{~g} / \mathrm{cm}^{3}$ were equilibrated in separate MD simulations and then inserted between the muscovite layers in contact with the surface. The number of water molecules on the surface characterizes the thickness of the interfacial water film, which can also be quantified as the coverage factor, $\theta$, i.e., the ratio of the total number of $\mathrm{H}_{2} \mathrm{O}$ molecules in the surface water film to the number of bridging oxygen atoms on the basal surface of muscovite [18]. The system analyzed in this study was prepared with $\theta=7.1$ and represented a relatively thick water film, where both the interfacial features of the structure and the bulk-water behavior emerging beyond $\theta \sim 3-4$ are well observed. Since the $\mathrm{Al} / \mathrm{Si}$ substitution in the tetrahedral layers were completely random, the $\mathrm{N}(\mathrm{H} / \mathrm{D})_{4}{ }^{+}$ions at the basal surface were initially pulled away to a distance $\sim 5-7 \AA$ above the surface into the aqueous solution and allowed to assume their preferred interfacial positions in the preliminary MD equilibration runs.

Molecular dynamics (MD) simulations were performed in the canonical NVT ensemble at $T=300 \mathrm{~K}$. The CLAYFF forcefield [36], which incorporates the SPC water model [37], was used to calculate the energies of all interatomic interactions in the system. 
The intermolecular interaction parameters for the ammonium ion, $\mathrm{N}(\mathrm{H} / \mathrm{D})_{4}{ }^{+}$, consistent with the SPC water model, were obtained from the literature [38]. They have already been examined extensively in the simulations of aqueous and bio-molecular systems $[38,39]$. The partial atomic charges and the intramolecular interaction parameters for ammonia used in our simulations are presented in Table 1 . A cutoff distance of $20 \AA$ was applied for the short range interactions, and the Ewald summation technique was used to account for the long range electrostatic interactions. A time step of $1 \mathrm{fs}$ was employed to integrate the equations of atomic motion, and the system was carefully equilibrated in a preliminary 1000 ps MD run, before the equlilibrium MD trajectory was generated for further statistical analysis. The structural properties were calculated from the outputs that were recorded every $10 \mathrm{fs}$ for that last 1000 ps part of the MD trajectory.

Near-surface structural details of the aqueous film were obtained by calculating the atomic density profiles for all atom types present in the simulation along the direction normal to the muscovite surface. The average positions of the bridging oxygens $\left(\mathrm{O}_{\mathrm{b}}\right.$ and $\left.\mathrm{O}_{\mathrm{bts}}\right)$ of the muscovite basal surface were computed and the plane corresponding to the average was considered as origin $(z=0)$ for the calculation of the atomic density profiles.

The structural and dynamical properties of all aqueous surface species are strongly influenced by the hydrogen bonding environment in the interfacial region, particularly by the H-bond formations between the adsorbates and the substrate surface. To quantify the parameters of the interfacial H-bonding network, we analyzed the instantaneous and timeaveraged numbers of $\mathrm{H}$-bonds that are either accepted or donated by both water molecules and ammonium ions at the interface. In addition, an analysis of the total fraction of H-bonds associated with each $\mathrm{N}(\mathrm{H} / \mathrm{D})_{4}{ }^{+}$ion and $\mathrm{H}_{2} \mathrm{O}$ molecule was performed. Following earlier work on the muscovite-water simulations $[13,26]$, we applied here the commonly used geometric criteria of H-bonding by which a hydrogen bond is established between any pairs of 
molecules if the intermolecular $\mathrm{O} \cdots \mathrm{H}$ distance is less than $2.45 \AA$ and the angle, $\beta$, between the $\mathrm{O} \cdots \mathrm{O}$ and $\mathrm{O}-\mathrm{H}$ vectors is less than $30^{\circ}$. The nitrogen atoms of ammonia and the oxygen atoms of the muscovite surface are accounted here as potential H-bond acceptors in exactly the same way as the oxygens of $\mathrm{H}_{2} \mathrm{O}$. Similarly, the $\mathrm{H}$ (or D) atoms of the $\mathrm{N}(\mathrm{H} / \mathrm{D})_{4}{ }^{+}$ions are treated as potential H-bond donors in exactly the same way as $\mathrm{H}$ of $\mathrm{H}_{2} \mathrm{O}$. In order to quantify the influence of the two different types of surface bridging oxygens $\left(\mathrm{O}_{\mathrm{b}}\right.$ and $\left.\mathrm{O}_{\mathrm{bts}}\right)$ on the coordination of $\mathrm{H}_{2} \mathrm{O}$ and $\mathrm{N}(\mathrm{H} / \mathrm{D})_{4}{ }^{+}$at the interface, we have studied their interaction separately. The hydration structure of $\mathrm{NH}_{4}{ }^{+}$(and $\mathrm{ND}_{4}{ }^{+}$for completeness' sake) ions was also characterized by calculations of the atom-atom radial distribution functions (RDF), and the corresponding running coordination numbers (RCN).

\section{Results and Discussion}

Surface Density Profiles

Atomic density profiles for the adsorbed $\mathrm{H}_{2} \mathrm{O}$ molecules and $\mathrm{N}(\mathrm{H} / \mathrm{D})_{4}{ }^{+}$ions normal to the muscovite surface characterize the preferred positions and orientations assumed by these species at the interface (Figure 2). They also illustrate to what degree the aqueous layer formation is influenced by the presence of randomly and uniformly distributed tetrahedral substitution sites on the muscovite surface.

It is clear from Figure 2 that the distribution of $\mathrm{N}$ in the $\mathrm{NH}_{4}{ }^{+}$and $\mathrm{ND}_{4}{ }^{+}$systems (yellow solid and dashed lines, respectively) are, as they must be, very similar with the first peak maxima located at $1.45 \AA$ away from the surface, with a minor contribution to the atomic density at distances between 2-3 $\AA$. The shapes and positions of $\mathrm{H}\left(\mathrm{NH}_{4}^{+}\right)$and D $\left(\mathrm{ND}_{4}{ }^{+}\right)$atomic density peaks (pink solid and dashed lines, respectively) are again similar to each other with the distributions having two peaks centered at $0.9 \AA$ and $2.3 \AA$. In addition, a significantly broader and asymmetric lower density distribution is observed at larger distances 
ranging between $2.8-3.7 \AA$. This shoulder is clearly correlated with the similar shoulder in $\mathrm{N}$ distribution above. The integral intensity of the first peak for both $\mathrm{H}$ and $\mathrm{D}$ distributions is more than twice higher in magnitude than the peak intensity of the nitrogen of $\mathrm{N}(\mathrm{H} / \mathrm{D})_{4}{ }^{+}$. On the other hand, the integral intensity of the second peak for both $\mathrm{H}$ and $\mathrm{D}$ of $\mathrm{N}(\mathrm{H} / \mathrm{D})_{4}{ }^{+}$is slightly greater than the peak intensity of the nitrogen of $\mathrm{N}(\mathrm{H} / \mathrm{D})_{4}{ }^{+}$. Taken together, these comparisons confirm that, at least in this respect, the sampling of our trajectory is fully sufficient [40] and that the conclusions are thus reliable: nearly 3 out of 4 hydrogens (or deuteriums) of the ammonia ions are strongly coordinated with the surface oxygens and the fourth one is pointing away from the surface and is coordinated with the water molecules at the interfacial region.

The density distribution of $\mathrm{O}_{\mathrm{H} 2 \mathrm{O}}$ clearly reveals five distinct positions of the water molecules at distances centered at 1.8, 2.7, 3.8, 5.4 and $6.2 \AA$ away from the muscovite surface (maroon solid and dashed lines, respectively). Meanwhile, the density distribution of $\mathrm{H}_{\mathrm{H} 2 \mathrm{O}}$ clearly shows five peak maxima at distances $1.6,3.2,4.3,5.8$ and $6.6 \AA$ away from the surface (green solid and dashed lines, respectively). In addition, a small shoulder is also noticeable close to the surface at $1.1 \AA$. It is evident from the distributions that the water molecules belonging to the first peak of the $\mathrm{O}_{\mathrm{H} 2 \mathrm{O}}$ density distribution at $1.8 \AA$ are associated with the plane of the surface $\mathrm{N}(\mathrm{H} / \mathrm{D})_{4}{ }^{+}$ions and exhibit correlations only with the surface bridging oxygen atoms $\left(\mathrm{O}_{\mathrm{b}}\right.$ and $\left.\mathrm{O}_{\mathrm{bts}}\right)$, but not with the ions. The intensity of the shoulder near $1.1 \AA$ seen in the $\mathrm{H}_{\mathrm{H} 2 \mathrm{O}}$ density distribution is larger by a factor of 2 than the integral intensity of the $1^{\text {st }}$ peak of $\mathrm{O}_{\mathrm{H} 2 \mathrm{O}}$, clearly indicating that both hydrogen atoms of this small fraction of the interfacial water molecules are coordinated with the surface.

At the same time, the distance between the $2^{\text {nd }}$ peak of $\mathrm{O}_{\mathrm{H} 2 \mathrm{O}}$ and $1^{\text {st }}$ peak of $\mathrm{H}_{\mathrm{H} 2 \mathrm{O}}$ is about $1 \AA$ (i.e., close to the intramolecular $\mathrm{O}-\mathrm{H}$ bond length), and the integral peak intensities for both distributions are highly similar. This allows us to conclude that the water molecules 
contributing to these peaks are oriented in such a way that they donate one H-bond to the muscovite surface, while the other H-bond is donated to the water molecules located above them (the $\mathrm{H}_{\mathrm{H} 2 \mathrm{O}}$ peak at $3.2 \AA$; green lines in Fig.2). At larger distances from the surface, the atomic density profiles for both $\mathrm{O}_{\mathrm{H} 2 \mathrm{O}}$ and $\mathrm{H}_{\mathrm{H} 2 \mathrm{O}}$ are gradually approaching the bulk water density distributions.

The density distributions of $\mathrm{O}_{\mathrm{H} 2 \mathrm{O}}$ also compare well with the X-ray reflectivity measurements [31]. Even though the experiments were performed with $\mathrm{K}^{+}$ions at the basal surface of muscovite, such a comparison is still quite meaningful, because the ionic radia of $\mathrm{K}^{+}$and $\mathrm{NH}_{4}{ }^{+}$are very similar $[41,42]$. The congruence with the experimental distribution has been attributed to the predominant role played by the basal surface bridging oxygen atoms on the mica surface [19]. Our atomic density profiles are also in generally good agreement with the results of earlier simulations [20, 23, 24, 26], and any discrepancies could be attributed to the random distribution of the surface cations and isomorphic Al substitution at the tetrahedral layer, compared to the more ordered distributions assumed in the earlier studies.

\section{Local Hydration Structure and the Surface Hydrogen Bonding Network}

The ammonium ions and their deuterated analogues located at the muscovite-water interface are always strongly coordinated by the $\mathrm{H}_{2} \mathrm{O}$ molecules, as it is clearly evident from the atom-atom RDFs and the corresponding coordination numbers $(\mathrm{CN})$ presented in Figure 3. At first glance, the oxygen-nitrogen RDFs look very much like the ones obtained from the simulations of ammonia hydration in a bulk aqueous solution [38]. However, the number of water molecules in the first hydration sphere of the surface ammonia (defined by the $3.55 \AA$ position of the first minimum of the RDF) is approximately 4 times lower than in the bulk: 1.5 and 5.9 [38], respectively. This can be attributed to the strong coordination of the surface $\mathrm{N}(\mathrm{H} / \mathrm{D})_{4}{ }^{+}$ions to the muscovite surface by their three hydrogens, thus leaving only one 
hydrogen to the coordination with water in the first hydration shell. These $\mathrm{H}_{2} \mathrm{O}$ molecules are contributing to the second and third peaks of $\mathrm{O}_{\mathrm{H} 2 \mathrm{O}}$ density profiles in Fig.2 and are not necessarily H-bonded to the ammonia ions. The RDFs and CNs calculated between the H/D of the surface ammonia ions and the oxygens of water (Fig. 3b) confirm this interpretation. The first RDF peak at $1.8 \AA$ is due to the H-bonded neighbors, and its integration gives a coordination number of about 0.37 , again indicating that, on average, only one out of four hydrogens of the surface $\mathrm{N}(\mathrm{H} / \mathrm{D})_{4}{ }^{+}$ions donates an $\mathrm{H}$-bond to the neighboring $\mathrm{H}_{2} \mathrm{O}$.

In the interfacial region, a well-interconnected hydrogen bonding network is formed by the $\mathrm{H}$-bonds donated by the $\mathrm{N}(\mathrm{H} / \mathrm{D})_{4}{ }^{+}$ions and $\mathrm{H}_{2} \mathrm{O}$ molecules to the basal surface of muscovite and by $\mathrm{H}$-bonds donated to the other $\mathrm{H}_{2} \mathrm{O}$ molecules. Hence, it is very instructive to quantitatively investigate the evolution of the local $\mathrm{H}$-bonding environment experienced by the interfacial aqueous species as a function of the distance from the muscovite surface, as represented in Figures 4 and 5. As above, also here, within the statistical uncertainty of our calculations, we observe no significant effect of the isotopic substitution on the interfacial structure of the $\mathrm{N}(\mathrm{H} / \mathrm{D})_{4}{ }^{+}$ions and the hydration water molecules (e.g., compare solid and dashed lines of the same color on Figs. 2, 4, and 5), which gives us trust also in these conclusions.

\section{H-bonding Environment of the Surface Ammonia Ions}

The average total number of $\mathrm{H}$-bonds experienced by a N(H/D $)_{4}{ }^{+}$ion varies between 3.3 to 4 in the entire interfacial region (yellow lines in Fig. 4a). This value is close to the bulk ammonia hydration [38] and indicates that all four of the ammonia hydrogens are involved in donating H-bonds most of the time. However, the nature of these H-bonds in our case is strongly dependent on the distance from the muscovite surface. Most closely to the surface, approximately two $\mathrm{H}$-bonds are donated to the surface $\mathrm{O}_{\mathrm{bts}}$ atoms surrounding the $\mathrm{Al} / \mathrm{Si}$ 
substitution (blue lines in Fig. 4a) and only one H-bond is donated to the regular bridging oxygens, $\mathrm{O}_{\mathrm{b}}$ (green lines in Fig. 4a). The former bonds are somewhat stronger and energetically more favorable than the latter ones since the $\mathrm{O}_{\mathrm{bts}}$ bears a more negative charge than the $\mathrm{O}_{\mathrm{b}}$. The fourth $\mathrm{H}$-bond of $\mathrm{N}(\mathrm{H} / \mathrm{D})_{4}{ }^{+}$is donated to a water molecule right above the ion (red lines in Fig. 4a). Consequently, at distances very close to the muscovite surface over $80 \%$ of all $\mathrm{N}(\mathrm{H} / \mathrm{D})_{4}{ }^{+}$ions form, on average, $4 \mathrm{H}$-bonds, while the rest are in a 3-bonded configuration; the contribution of 2-bonded and 1-bonded configurations is nearly negligible.

As the separation from the muscovite surface increases, the H-bonding coordination of the $\mathrm{N}(\mathrm{H} / \mathrm{D})_{4}{ }^{+}$ions to water molecules increases at the expense of their coordination to both types of the surface bridging oxygen atoms. At distances $2 \AA$ away from the surface, the $\mathrm{N}(\mathrm{H} / \mathrm{D})_{4}{ }^{+}$ion already donates $1.6 \mathrm{H}$-bonds to the neighboring $\mathrm{H}_{2} \mathrm{O}$ molecules and only $1.3 \mathrm{H}$ bonds to $\mathrm{O}_{\mathrm{bts}}$ and $0.7 \mathrm{H}$-bonds to $\mathrm{O}_{\mathrm{b}}$ (Fig. 4a). This evolution of the $\mathrm{N}(\mathrm{H} / \mathrm{D})_{4}{ }^{+}$ion's local $\mathrm{H}$ bonding environment decreases the fraction of 4-bonded species on the surface from $80 \%$ to $50 \%$ and enhances the fraction of 3 -bonded species to $35 \%$ (Fig. $4 \mathrm{~b}$ ). As the ion-surface separation increases beyond $2 \AA$, where a flat density distribution is observed (see Fig. 2), $\mathrm{N}(\mathrm{H} / \mathrm{D})_{4}{ }^{+}$ion donates only one $\mathrm{H}$-bond to the $\mathrm{O}_{\mathrm{bts}}$ surface oxygen and its coordination to water molecules increases to three $\mathrm{H}$-bonds at the expense of $\mathrm{O}_{\mathrm{b}}$ basal oxygen coordination. This indicates that the small fraction of the ammonium ions present at such larger separations assume an inverted orientation with only one $\mathrm{H}$ atom pointing towards the surface. In this relatively stable configuration the fraction of the 4-bonded ions again becomes dominant in the system $(65 \%)$.

However, it is interesting to note that the narrow range of ion-surface separations between 2.1 and $2.4 \AA$ can be considered as an unstable transition region, where the N(H/D $)_{4}{ }^{+}$ ions lose their H-bonds to the surface but cannot yet form relatively stable new H-bonds to the $\mathrm{H}_{2} \mathrm{O}$ molecules. Consequently, the fraction of 4-bonded species at these separations decreases 
quite dramatically in favor of the 3-bonded and 2-bonded species, decreasing the average total number of $\mathrm{H}$-bonds to a minimum of 3.2. As the result of this "under-bonding", one should also expect some increase in the positional and orientational mobility of the the N(H/D) ${ }_{4}{ }^{+}$ions in this transition layer of the aqueous film on ammonia-muscovite.

It is also equally important to note that only a statistically negligible fraction of the ions was observed as capable of fully escaping the surface and assuming a completely hydrated configuration as an outer-sphere surface complex coordinated to four $\mathrm{H}_{2} \mathrm{O}$ molecules.

\section{H-bonding Environment of the Interfacial Surface Water Molecules}

It is clearly apparent from the MD simulations that the average number of H-bonds per $\mathrm{H}_{2} \mathrm{O}$ molecule decreases from 4 in the near-surface region to 3.5 at distances greater than $6 \AA$ from the muscovite surface (Fig. 5a). This latter value is close to the average H-bonding configuration of $\mathrm{H}_{2} \mathrm{O}$ molecules in bulk liquid water $[13,26]$. At these distances an equivalent balance between the average numbers of accepted and donated H-bonds formed by each water molecule is also established, because away from the surface they only form H-bonds among themselves (Fig. 5b). However, the near-surface $\mathrm{H}_{2} \mathrm{O}$ molecules contributing to the first peak of the oxygen density profile (see Fig.2), on average, donate $2 \mathrm{H}$-bonds to basal oxygens (1.5 to $\mathrm{O}_{\mathrm{bts}}$ and 0.5 to $\mathrm{O}_{\mathrm{b}}$ ) and accept $2 \mathrm{H}$-bonds from the other water molecules resulting in the total number of H-bonds approaching 4. Despite the resemblance with the ice-like H-bonding coordination, the water molecules in this group exhibit different types of H-bonding topology: about $50-60 \%$ of them participate, on average, in $4 \mathrm{H}$-bonds, while $30-45 \%$ participate in $3 \mathrm{H}-$ bonds, and the fraction of "over-bonded" 5-coordinated molecules is as high as $20 \%$. The water molecules contributing to the first peak of the $\mathrm{O}_{\mathrm{H} 2 \mathrm{O}}$ density profile on Fig.2 do not form 
H-bonds with the interfacial $\mathrm{N}(\mathrm{H} / \mathrm{D})_{4}{ }^{+}$ions and coordinate only to the basal surface of muscovite.

As the distance from the surface increases, the water molecules contribution to the second peak of $\mathrm{O}_{\mathrm{H} 2 \mathrm{O}}$ density profiles have significant but fluctuating coordination to the basal oxygen atoms of both types $\left(\mathrm{O}_{\mathrm{bts}}\right.$ and $\left.\mathrm{O}_{\mathrm{b}}\right)$. These $\mathrm{H}_{2} \mathrm{O}$ molecules, on average, accept $\sim 2 \mathrm{H}$ bonds and donate $1 \mathrm{H}$-bond to other water molecules, amounting to the total of $3.5 \mathrm{H}$-bonds per molecule, out of which $35-50 \%$ are found in 4-bonded and 3-bonded configurations whereas 5-10\% represent 2-bonded and 5-bonded species each (Fig.5). The water molecules contributing to the third peak of $\mathrm{O}_{\mathrm{H} 2 \mathrm{O}}$ density profiles donate, on average, 1.5-1.7 H-bonds to other $\mathrm{H}_{2} \mathrm{O}$ molecules, accept 1.0-1.5 H-bonds from other $\mathrm{H}_{2} \mathrm{O}$ molecules and accept $0.5 \mathrm{H}$ bond from the interfacial $\mathrm{N}(\mathrm{H} / \mathrm{D})_{4}{ }^{+}$ions. Overall, this amounts to $3.3 \mathrm{H}$-bonds per water molecule out of which 30-40\% represent 4-bonded species, 40-50\% - 3-bonded species, 20$30 \%$ - 2-bonded species and the fraction of 1-bonded species reaches its maximum of $5 \%$.

Thus, there are 3 unstable transition regions in the coordination of interfacial water molecules as a function of their distance from the surface. In the range between 2.0 and $2.5 \AA$ they, on average, lose one of their $\mathrm{H}$-bonds to the surface, which requires their re-orientation and also results in the local minimum of the total number of $\mathrm{H}$-bonds per molecule (Fig.5a) and the dominance of the 3-bonded species (Fig.5b). In the second such transition layer, approximately between 2.8 and $3.6 \AA$ the water molecules lose their second H-bond to the surface, which again requires their re-orientation and results in the global minimum of the total number of $\mathrm{H}$-bonds per molecule $\sim 3.0$ (Fig.5a) and the significant decrease of the fraction of the most favorably coordinated 4-bonded species (Fig.5b). In this range of surface separations, the $\mathrm{H}_{2} \mathrm{O}$ molecules are becoming more actively involved in the hydration of the interfacial $\mathrm{N}(\mathrm{H} / \mathrm{D})_{4}{ }^{+}$ions, while the final loss of their coordination to the ammonia ions at 
distances $\sim 4.6-5.4 \AA$ from the surface corresponds to the third transition layer after which the $\mathrm{H}_{2} \mathrm{O}$ molecules form $\mathrm{H}$-bonds only with each other.

\section{Conclusions}

Molecular dynamics simulations of the structural and hydrogen-bonding properties of $\mathrm{N}(\mathrm{H} / \mathrm{D})_{4}{ }^{+}$ions and water molecules adsorbed on the (001) surface of muscovite mica show that under ambient conditions, both the $\mathrm{N}(\mathrm{H} / \mathrm{D})_{4}{ }^{+}$ions and the very first molecular layer of $\mathrm{H}_{2} \mathrm{O}$ form $\mathrm{H}$-bonds only with the basal surface of muscovite, but not with each other. At distances very close to the surface, the $\mathrm{N}(\mathrm{H} / \mathrm{D})_{4}{ }^{+}$ions donate $3 \mathrm{H}$-bonds to the surface bridging oxygens and one to the water molecules above them, whereas the water molecules nearest to the surface also donate both their hydrogens to H-bonds with the surface bridging oxygens and accept two H-bonds from other water molecules above them. As the distance from the surface increases, the $\mathrm{H}$-bonds with the surface of both $\mathrm{N}(\mathrm{H} / \mathrm{D})_{4}{ }^{+}$and $\mathrm{H}_{2} \mathrm{O}$ are gradually replaced by the $\mathrm{H}$-bonds to the neighboring water molecules, with the ammonia ions experiencing one reorientational transition region, while the $\mathrm{H}_{2} \mathrm{O}$ molecules experiencing three such consecutive transitions. The structural results obtained from our simulations are consistent with the experimental IR studies of $\mathrm{NH}_{4}{ }^{+}$-bearing clay minerals [43]. The variation of the masses of some particles (H/D) shows that our structural quantities are well converged. Isotope effects are of course expected in the vibrational, re-orientational and diffusional mobility of the surface species, which be the subject of further studies.

\section{Acknowledgements}

This work was supported by the industrial chair "Storage and Management of Nuclear Waste" at the Ecole des Mines de Nantes, funded by ANDRA, Areva, and EDF. Generous allocations of HPC resources at the DEISA (grant DEC07_NUWCLAY) and GENCI (grant 2012096921) 
facilities are also gratefully acknowledged. 


\section{References}

[1] P. Fenter and N. C. Sturchio, Progress in Surface Science 77, 171 (2004).

[2] M. J. Higgins, M. Polcik, T. Fukuma, J. E. Sader, Y. Nakayama and S. P. Jarvis, Biophys. Journal, 91, 2532 (2006).

[3] J. Israelachvili and R. Pashley, Nature 300, 341 (1982).

[4] E. H. Rutter, R. H. Maddock, S. H. Hall and S. H. White, Pure and Appl. Geophys. 124, 3 (1986).

[5] M. L. Schlegel, K. L. Nagy, P. Fenter, L. Cheng, N. C. Sturchio and S. D. Jacobsen, Geochim. Cosmochim. Acta 70, 3549 (2006).

[6] C. A. J. Appelo, A. Vinsot, S. Mettler and S. Wechner, J.Contaminant Hydrol. 101, 67 (2008).

[7] J. A. Davis and D. B. Kent, Reviews in Mineralogy 23, 177 (1990).

[8] M. Ochs, M. Boonekamp, H. Wanner, H. Satp and M. Yui, Radiochim. Acta 82, 437 (1998).

[9] C. Park, P. A. Fenter, K. L. Nagy and N. C. Sturchio, Phys. Rev. Lett. 97, 016101 (2006)

[10] G. E. Brown, V. E. Henrich, W. H. Casey, D. L. Clark, C. Eggleston, A. Felmy, D. W. Goodman, M. Grätzel, G. Maciel, M. I. McCarthy, K. H. Nealson, D. A. Sverjensky, M. F. Toney and J. M. Zachara, Chem. Rev. 99, 77 (1998).

[11] M. A. Henderson, Surf. Sci. Repts 46, 1 (2002).

[12] J. Wang, A. G. Kalinichev and R. J. Kirkpatrick, Geochim. Cosmochim. Acta 70, 562 (2006).

[13] J. Wang, A. G. Kalinichev and R. J. Kirkpatrick, J. Phys. Chem. C 113, 11077 (2009).

[14] T. E. Balmer, H. K. Christenson, N. D. Spencer and M. Heuberger, Langmuir 24, 1566 (2007). 
[15] S. S. Lee, P. Fenter, C. Park, N. C. Sturchio and K. L. Nagy, Langmuir 26, 16647 (2010).

[16] S. S. Lee, P. Fenter, C. Park, N. C. Sturchio and K. L. Nagy, Geochim. Cosmochim. Acta 74, 1762 (2010).

[17] P. B. Miranda, L. Xu, Y. R. Shen and M. Salmeron, Phys. Rev. Lett. 81, 5876 (1998).

[18] W. C. Cantrell and G. E. Ewing, J. Phys. Chem. B 105, 5434 (2001).

[19] Y. Leng and P. T. Cummings, J. Chem. Phys. 124, 074711 (2006).

[20] A. Malani and K. G. Ayappa, J. Phys. Chem B 113, 1058 (2009).

[21] A. Meleshyn, J. Phys. Chem. C 112, 20018 (2008).

[22] A. Meleshyn, Langmuir 26, 13081 (2010).

[23] S.-H. Park and G. Sposito, Phys. Rev. Lett. 89, 085501 (2002).

[24] H. Sakuma and K. Kawamura, Geochim. Cosmochim. Acta 73, 4100 (2009).

[25] H. Sakuma and K. Kawamura, Geochim. Cosmochim. Acta 75, 63 (2011).

[26] J. Wang, A. G. Kalinichev, R. J. Kirkpatrick and R. T Cygan, J. Phys. Chem B 109, 15893 (2005).

[27] R. T. Cygan, J. A. Greathouse, H. Heinz and A. G. Kalinichev, J. Mater. Chem. 19, 2470 (2009).

[28] S. Ohnishi and A. M. Stewart, Langmuir 18, 6140 (2002).

[29] D. Beaglehole, Physica A 244, 40 (1997).

[30] D. Beaglehole and H. K. Christenson, J. Phys. Chem 96, 3395 (1992).

[31] L. Cheng, P. Fenter, K. L. Nagy, M. L. Schlegel and N. C. Sturchio, Phys. Rev. Lett. 87, $156103(2001)$

[32] S. Higashi, Appl. Clay Sci. 16, 171 (2000).

[33] A. G. Kalinichev, P. P. Kumar and R. J. Kirkpatrick, Philos. Magazine 90, 2475 (2010) 
[34] G. M. Bowers, D. L. Bish and R. J. Kirkpatrick, Langmuir 24, 10240 (2008).

[35] A. Beran, Rev. Mineral. Geochem 46, 351 (2002).

[36] R. T. Cygan, J.-J. Liang and A. G. Kalinichev, J. Phys. Chem. B 108, 1255 (2004).

[37] W. L. Jorgensen, J. Chandrasekhar, J. D. Madura, R. W. Impey and M. L. Klein, J. Chem. Phys. 79, 926 (1983).

[38] W. L. Jorgensen, J. Gao, J. Phys. Chem 90, 2174 (1986).

[39] M. Mustafa, D. J. Henderson and D. D. Busath, Proteins: Structure, Function, and Bioinformatics 76, 794 (2009).

[40] J.N Canongia-Lopes and G. Jancsó, J.Mol.Phys. 112, 147 (2004).

[41] Y. Marcus, Chemical Reviews 88, 1475 (1988).

[42] H. Ohtaki and T. Radnai, Chemical Reviews 93, 1157 (1993).

[43] S. Petit, D. Righi and J. Madejova, Appl. Clay Sci. 34, 22 (2006). 
Table 1. Potential parameters for ammonium ion

Electrostatics Elements Partial charge

Nitrogen

$-0.35|e|$

Hydrogen/Deuterium

$0.40|e|$

Stretching

Bonded Elements Bond length $(\AA)$

$\mathrm{K}_{\mathrm{b}}\left(\mathrm{kcal} / \mathrm{mol} . \mathrm{A}^{2}\right)$

$\mathrm{N}-(\mathrm{H} / \mathrm{D})$

1.003

403.0

Bending

Bending Elements Bond Angle $\left(^{0}\right.$ )

$\mathrm{K}_{\theta}\left(\mathrm{kcal} / \mathrm{mol} . r a d^{2}\right)$

$(\mathrm{H} / \mathrm{D})-\mathrm{N}-(\mathrm{H} / \mathrm{D}) \quad 109.47^{\circ}$

44.0 


\section{Figure captions}

Figure 1. (a) Schematic representation of the hydrated $\mathrm{N}(\mathrm{H} / \mathrm{D})_{4}{ }^{+}-$muscovite surface. (b) Distribution of the $\mathrm{Al}$ tetrahedral sites and the ammonia ions on the hydrated muscovite surface: $\mathrm{Si}$ - yellow sticks, $\mathrm{O}$ - red sticks, $\mathrm{Al}$ - green balls, $\mathrm{N}$ - blue balls, and (H/D) - white balls. For clarity, only one tetrahedral layer is shown and all $\mathrm{H}_{2} \mathrm{O}$ molecules have been removed.

Figure 2. Atomic density profiles of the aqueous species at the muscovite surface. Solid lines $-\mathrm{NH}_{4}{ }^{+}$system, dashed lines $-\mathrm{ND}_{4}{ }^{+}$system. The zero position is defined as the average $z$-coordinate of the surface bridging oxygen atoms (light blue). The other atoms are color coded as: N(ammonia) - orange, H/D(ammonia) - pink, $\mathrm{O}($ water $)$ - maroon, $\mathrm{H}($ water $)$ - green.

Figure 3. Radial distribution functions and running coordination numbers for: (a) $\mathrm{O}$ of water and $\mathrm{N}$ of ammonia; (b) $\mathrm{O}$ of water and (H/D) of ammonia. Red and blue lines $-\mathrm{NH}_{4}{ }^{+}$system, black solid and dashed lines $-\mathrm{ND}_{4}{ }^{+}$system.

Figure 4. Distribution of hydrogen bonds formed by ammonia ions at the hydrated muscovite surface. (a) Average number of bonds donated to $\mathrm{H}_{2} \mathrm{O}$ molecules (red), donated to surface $\mathrm{O}_{\mathrm{bts}}$ atoms (blue), donated to surface $\mathrm{O}_{\mathrm{b}}$ atoms (green), total (dark yellow). (b) Fractions of surface ammonia ions having, on average, $1 \mathrm{H}$ bond (black), 2 H-bonds (red), 3 H-bonds (green), 4 H-bonds (dark blue), and 5 H-bonds (light blue. Solid lines $-\mathrm{NH}_{4}{ }^{+}$system, dashed lines $-\mathrm{ND}_{4}{ }^{+}$system. 
Figure 5. Distribution of hydrogen bonds formed by $\mathrm{H}_{2} \mathrm{O}$ molecules at the hydrated ammonia-muscovite surface. (a) Average number of bonds donated to other $\mathrm{H}_{2} \mathrm{O}$ molecules (red), accepted from other $\mathrm{H}_{2} \mathrm{O}$ molecules (black), donated to surface $\mathrm{O}_{\mathrm{b}}$ atoms (blue), donated to surface $\mathrm{O}_{\mathrm{bts}}$ atoms (green), accepted from ammonia ions (light blue), total (dark yellow). (b) Fractions of surface $\mathrm{H}_{2} \mathrm{O}$ molecules having, on average, $1 \mathrm{H}$-bond (black), $2 \mathrm{H}$-bonds (red), $3 \mathrm{H}$-bonds (green), $4 \mathrm{H}$ bonds (dark blue), and $5 \mathrm{H}$-bonds (light blue). Solid lines $-\mathrm{NH}_{4}{ }^{+}$system, dashed lines $-\mathrm{ND}_{4}{ }^{+}$system. 
(a)

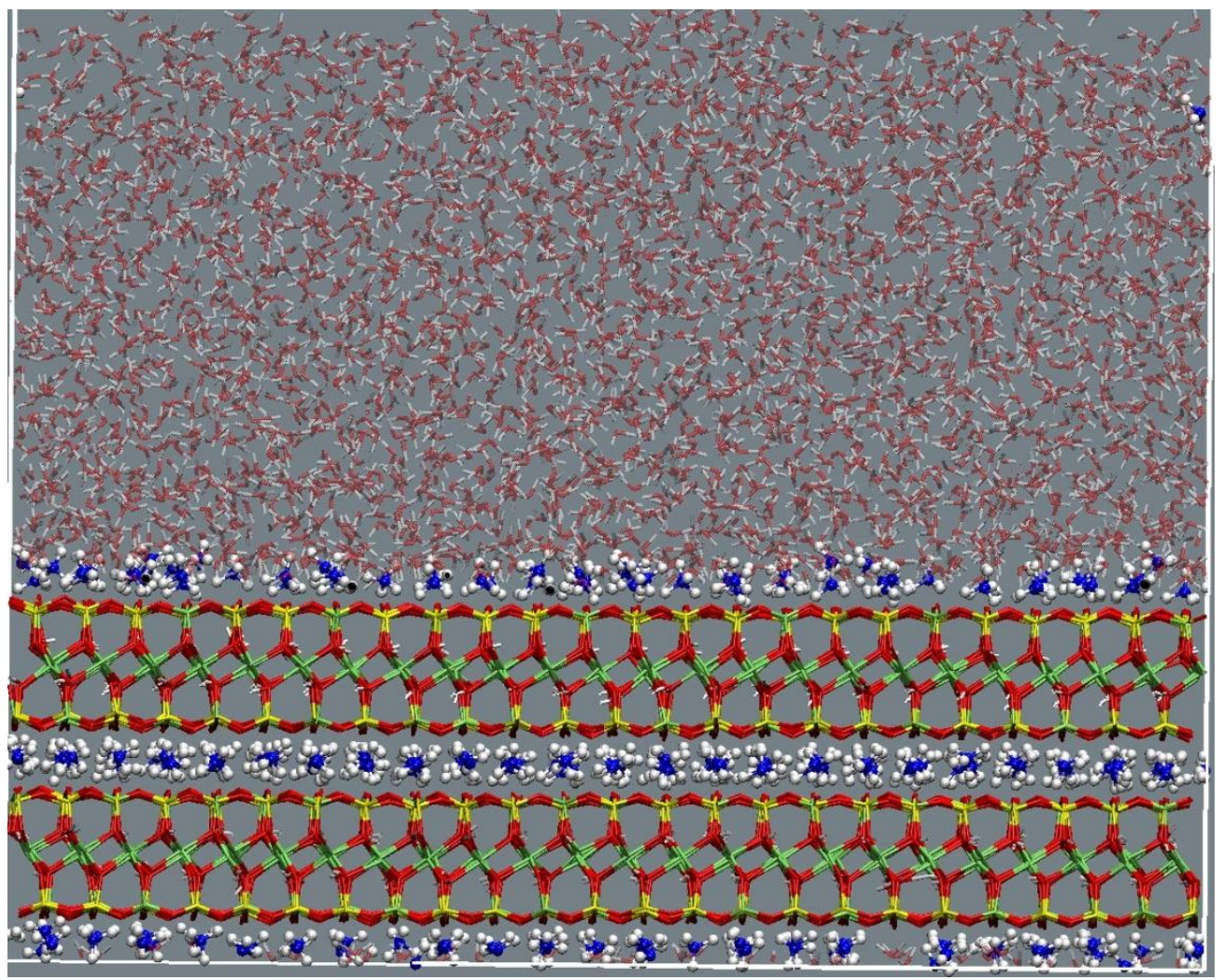

(b)

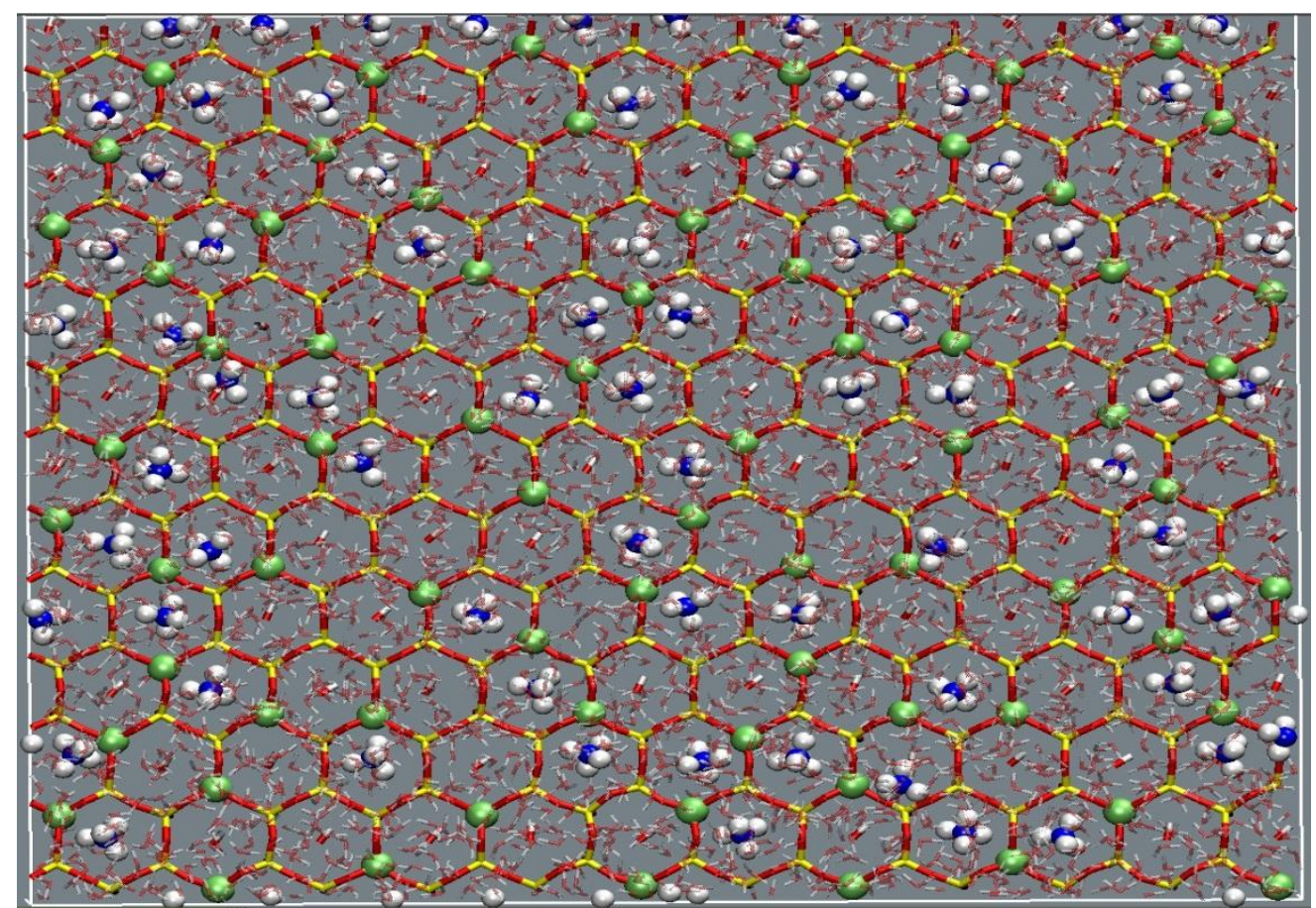

Figure 1 


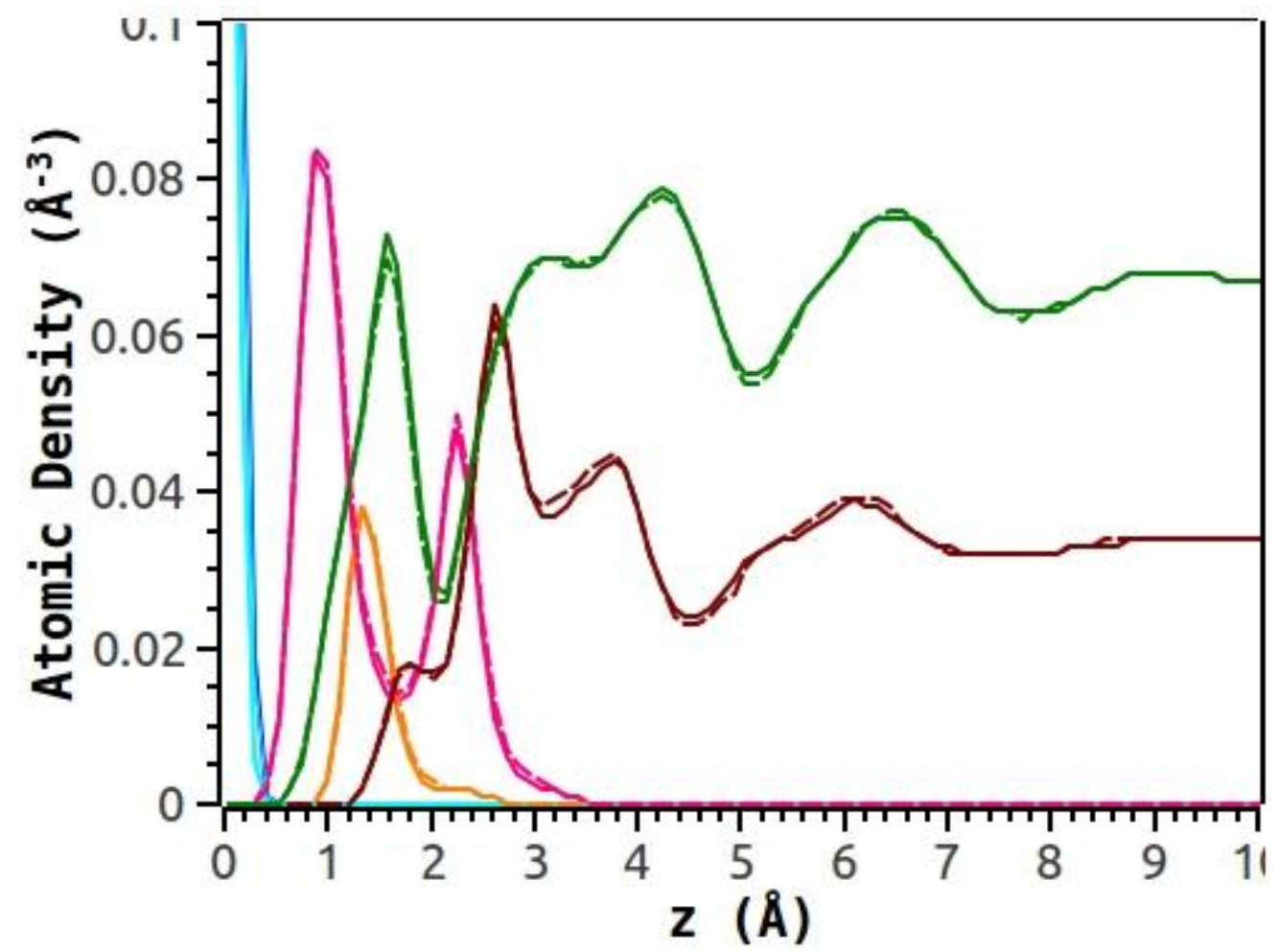

Figure 2 
(a)

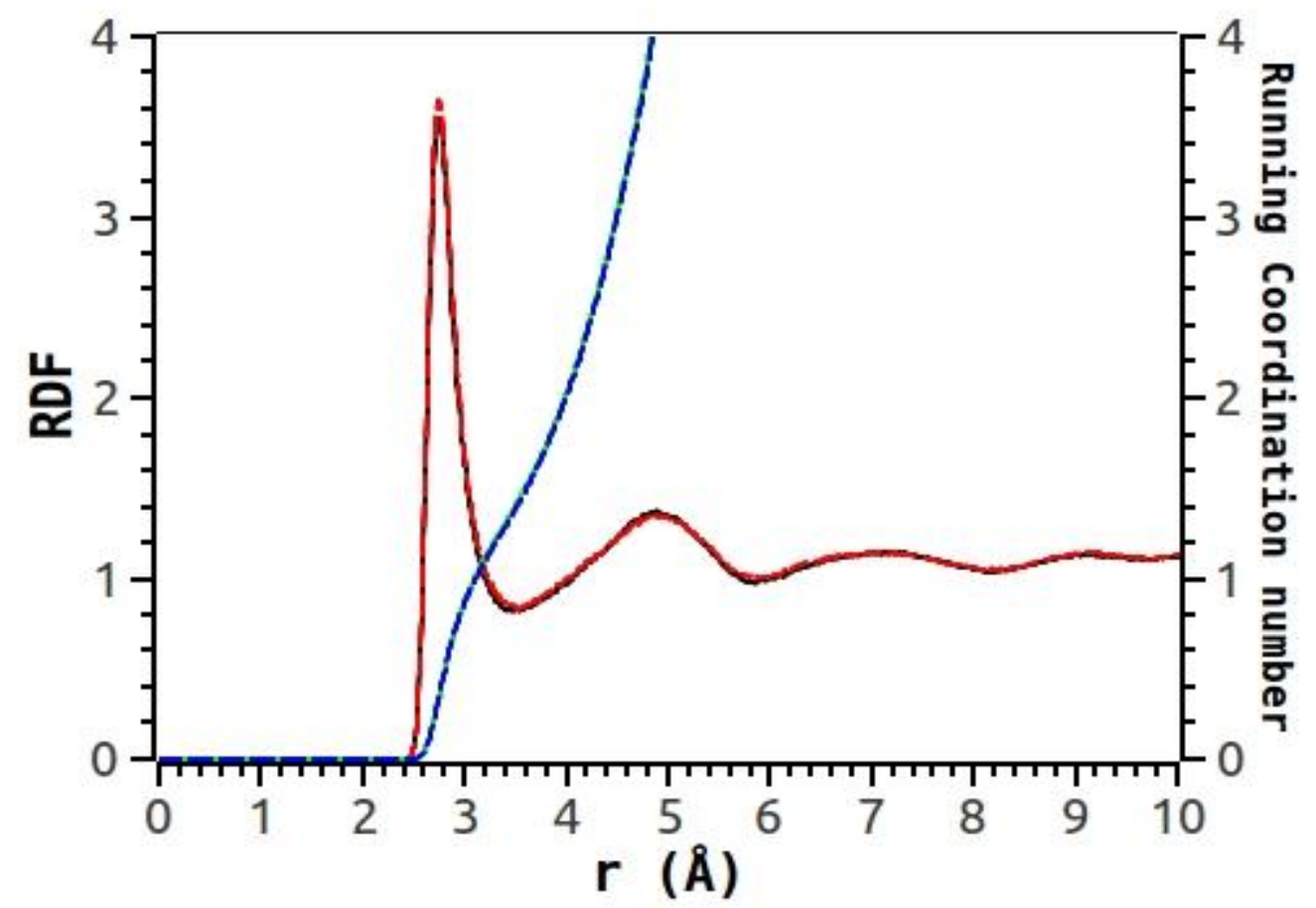

(b)

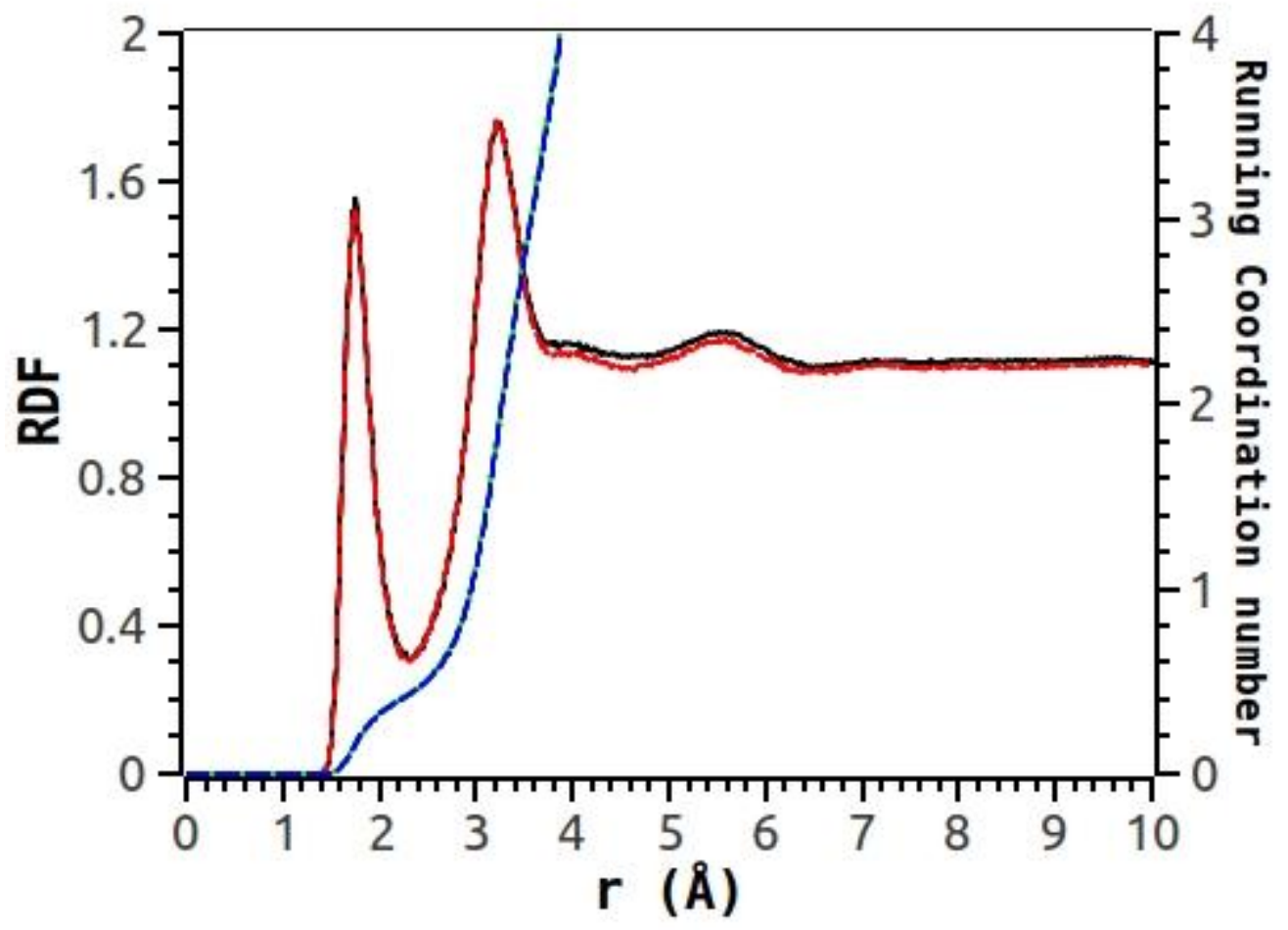

Figure 3 
(a)

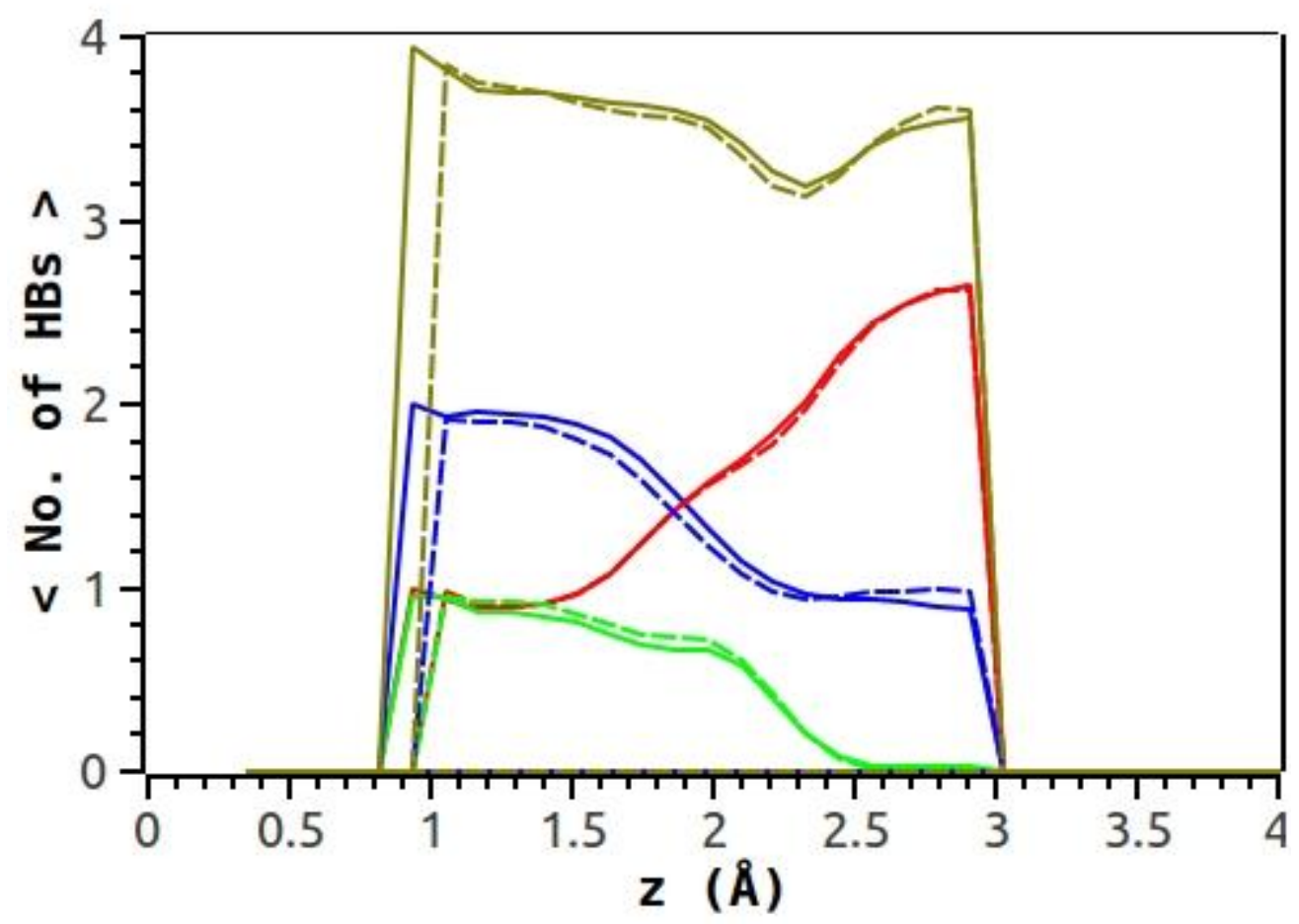

(b)

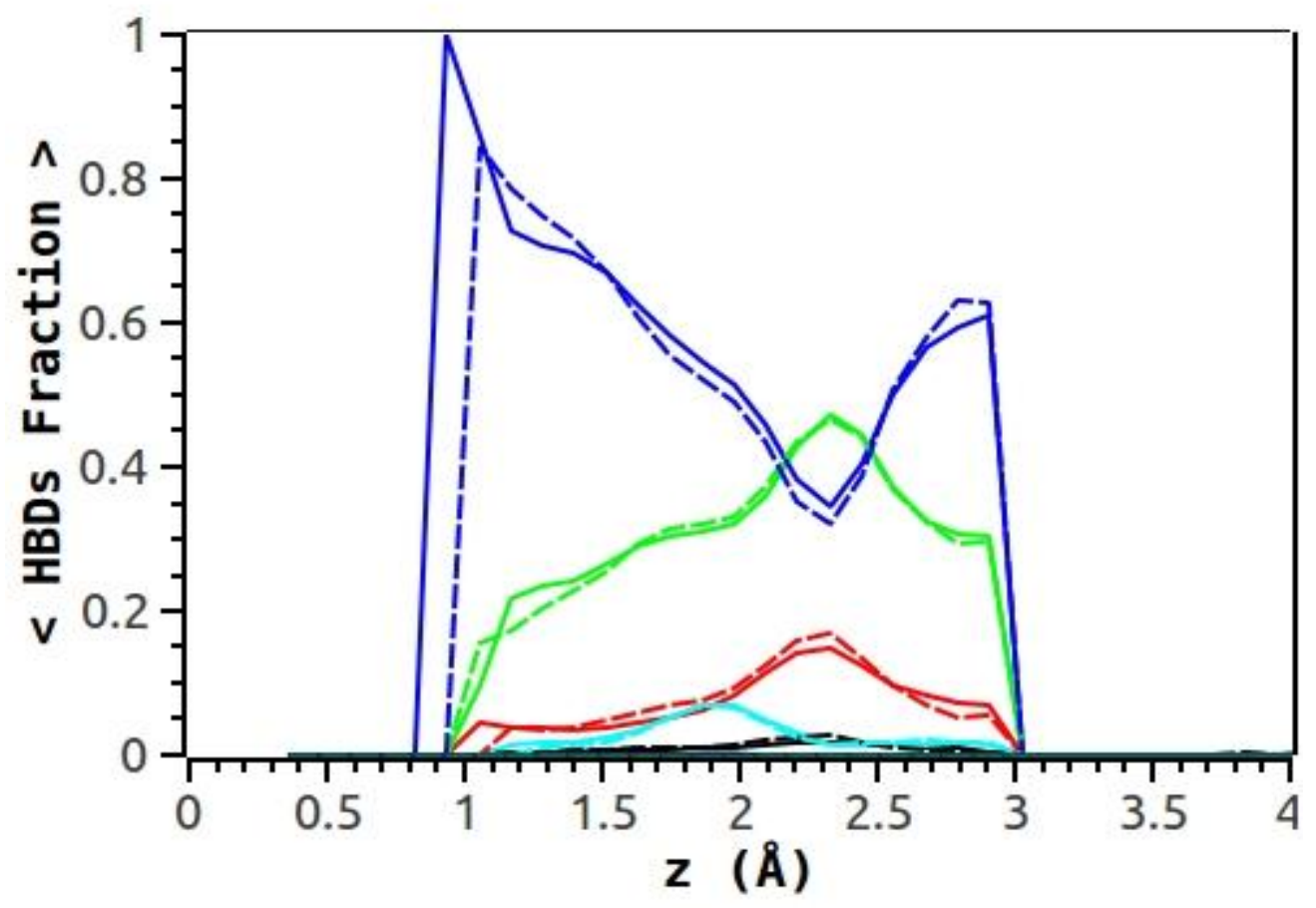

Figure 4 
(a)

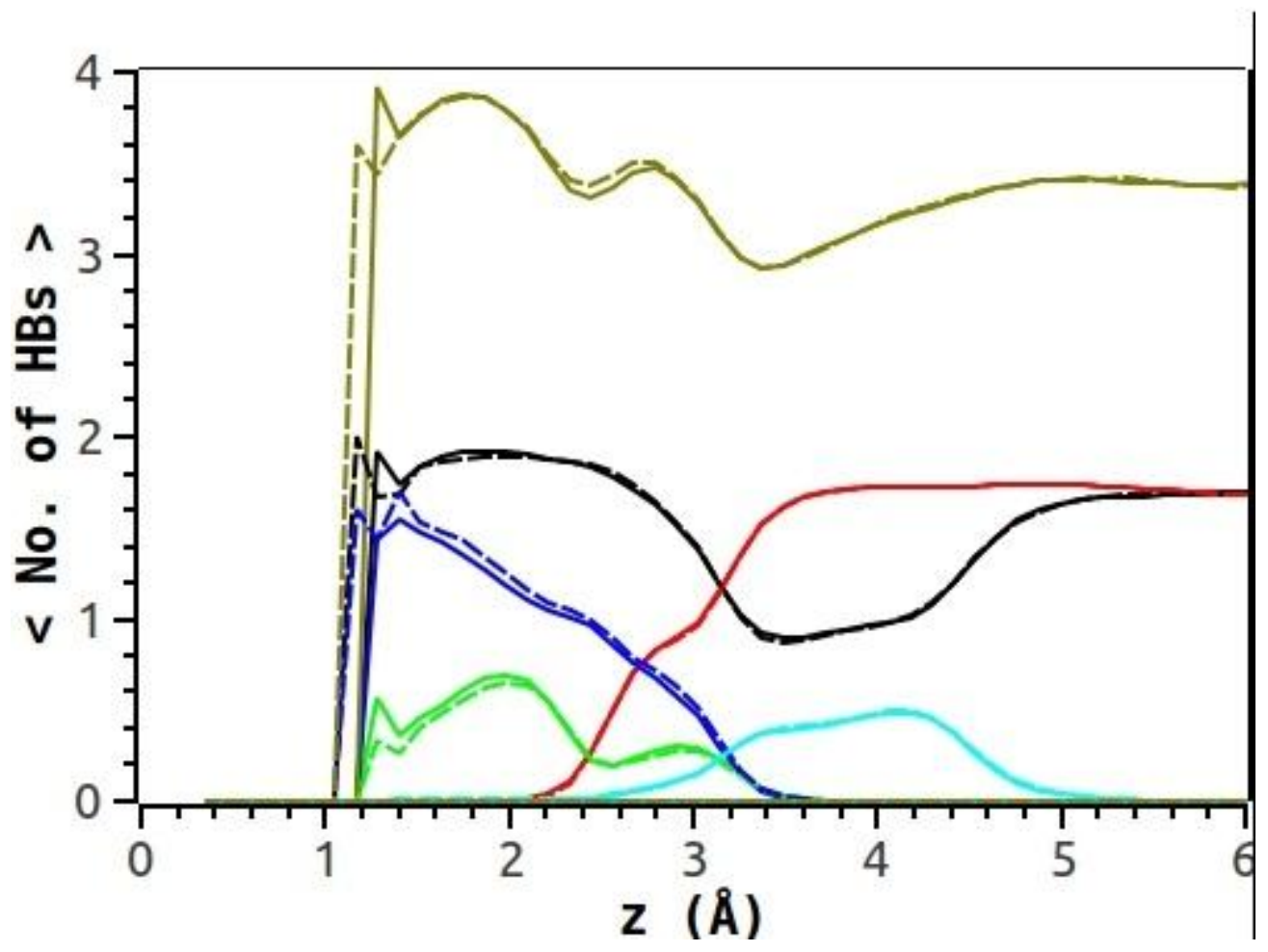

(b)

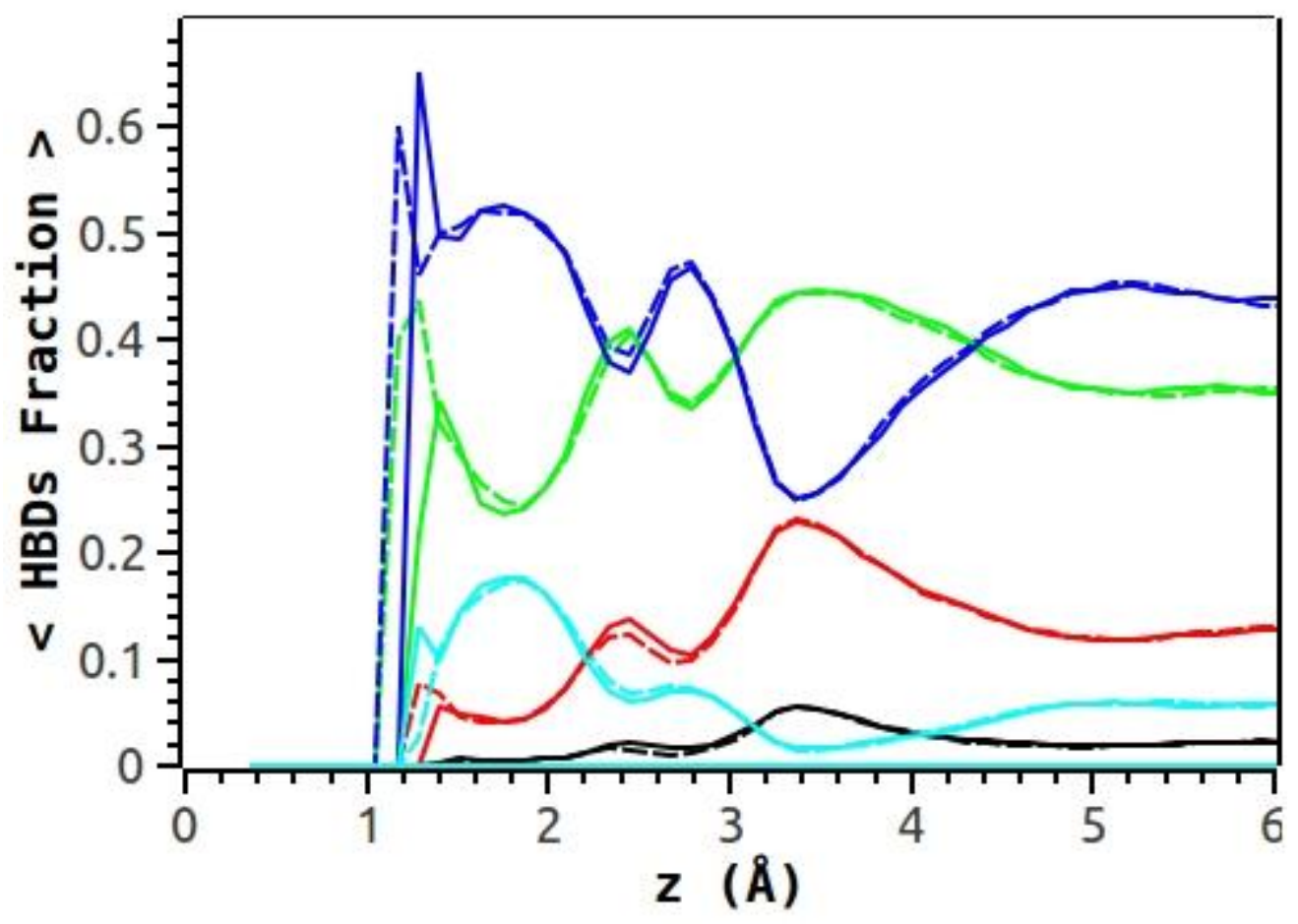

Figure 5 